\title{
Pre- and post-diagnosis physical activity is associated with survival benefits of colorectal cancer patients: a systematic review and meta-analysis
}

\author{
Wenrui Wu ${ }^{1,2}$, Feifei Guo ${ }^{1,2}$, Jianzhong $\mathrm{Ye}^{1,2}$, Yating $\mathrm{Li}^{1,2}$, Ding Shi ${ }^{1,2}$, Daiqiong \\ Fang $^{1,2}$, Jing Guo ${ }^{1,2}$, Lanjuan Li ${ }^{1,2}$ \\ ${ }^{1}$ State Key Laboratory for Diagnosis and Treatment of Infectious Diseases, The First Affiliated Hospital, School of Medicine, \\ Zhejiang University, Hangzhou, China \\ ${ }^{2}$ Collaborative Innovation Center for Diagnosis and Treatment of Infectious Diseases, Hangzhou, China \\ Correspondence to: Lanjuan Li, email: Ijli@zju.edu.cn
}

Keywords: physical activity, pre-diagnosis, post-diagnosis, colorectal cancer

Received: April 03, 2016

Accepted: June 29, 2016

Published: July 18, 2016

\section{ABSTRACT}

Objective: Physical activity is associated with reduced risk of colorectal cancer. However, whether physical activity could impart cancer patients' survival benefits remains uncertain. The aim of this study is to systematically evaluate the relationship between physical activity and colorectal cancer mortality.

Results: Our meta-analysis included 11 studies involving 17,295 patients with a follow-up period ranging from 3.8 to 11.9 years. Results indicated that physical activity was inversely associated with overall $(R R=0.81,95 \% \mathrm{CI}=0.72-0.91)$ and colorectal cancer-specific mortality $(R R=0.79,95 \% \mathrm{CI}=0.71-0.89)$ before the diagnosis of cancer, respectively. For physical activity after diagnosis, the pooled RRs of colorectal cancer-specific and total mortality were 0.77 (95\% CI, $0.63-0.94$ ) and 0.71 (95\% CI, 0.63-0.81), respectively. Similar inverse associations between exercise and prognosis were found among colorectal cancer survivors who had highlevel exercise compared with those who had low-level exercise or were inactive. There was no obvious evidence for publication bias among studies.

Materials and Methods: We performed a systematic data search in PubMed, Cochrane Library databases and Web of Science for relevant articles before Jan 2016. We adopted adjusted estimates to calculate pooled relative risks (RRs) with $95 \%$ confidence intervals ( $\mathrm{CI}$ ) by the random-effects model. The publication bias was assessed by Begg's test.

Conclusions: Our meta-analysis provides comprehensive evidence that physical activity, whether before or after the diagnosis of colorectal cancer, is related to reduced overall and cancer-specific mortality. Our findings may have significant public health implications and more prospective randomized clinical trials should be warranted to certify this protective association.

\section{INTRODUCTION}

Colorectal cancer (CRC) still represents one of most common malignances and a leading cause of cancer-related deaths globally, which accounts for over 1.2 million new colorectal cancer patients and 608,700 deaths in 2008 [1]. Due to advances in early diagnosis and comprehensive treatments, the 1-year relative survival rates of CRC have reached $83.4 \%$ [2]. However, 5-year survival rates were still $64.9 \%$ and long-term prognosis of CRC was poor [3].
Therefore, there is an urgent need to adopt measures to reduce the incidence of cancer recurrence and mortality among colorectal cancer survivors.

Accumulating evidence from epidemiologic studies has indicated that some modifiable lifestyle factors, such as physical activity, were linked with reduced incidence of colorectal cancer and a higher level of exercise among cancer survivors might contribute to lots of health benefits for these individuals [4-6]. However, the relationship between physical activity 
and prognosis of colorectal cancer remains inadequately understood. Although several prospective cohort studies had found the inverse association between exercise and total or cancer-specific mortality among patients [7-11]. Controversies still remained regarding different timing point of physical activity assessment and survival outcome measurements. The results from studies that post-diagnostic exercise was related to favorable survival outcomes were consistent [8, 10, 12, 13]. For example, Kuiper et al. [13]. reported that postdiagnosis physical activity could reduce cancer-specific and overall mortality among CRC patients. However, whether the pre-diagnostic physical activity could affect CRC survival was less conclusive. Some studies reported a favorable relationship between pre-diagnostic activity and prognosis of CRC $[8,14]$, while others indicated no significant association. For example, Meyerhardt et al. [10] reported that physical activity before the diagnosis was not associated with better prognosis among CRC survivors. Furthermore, it remains uncertain whether the beneficial effect of physical activity on CRC survival was influenced by other factors.

Considering these controversial contexts, we performed a systematic review and meta-analysis based on existing evidence to test and determine whether preor post- physical activity could influence cancer-specific and total mortality in order to better understand the effects of physical activity interventions on prognosis of CRC survivors.

\section{RESULTS}

\section{Literature search and study characteristics}

Our literature search yielded 562 articles in PubMed, Cochrane Library databases, Web of Science and manual search. After screening titles and abstracts of articles, 31 articles were reviewed with full texts. Finally, 11 prospective articles [7-17] were included in this metaanalysis and other twenty articles were excluded because they provided insufficient or overlapping information. Details of the selection process for studies were shown in Figure 1. The total number of participants in the metaanalysis was 17,295 with a follow-up period ranging from 3.8 to 11.9 years (Table 1). Among them, eight articles reported the association between physical activity before the diagnosis and CRC outcomes and seven studies presented CRC mortality in relation to physical activity after the diagnosis. Exposure assessment of physical activity was based on self-reported or interviewbased across studies. The level of physical activity was accessed as MET-hours per week or hours per week. The overall methodological quality of included studies was moderate to high using the Newcastle-Ottawa scale quality tool (Table 2).

\section{Association of physical activity with colorectal cancer mortality}

Among eight studies that assessed physical activity before the diagnosis in relation to prognosis, we observed that exercisers had lower colorectal cancerspecific mortality and overall mortality $(\mathrm{RR}=0.81,95 \%$ CI $0.72-0.91 ; \mathrm{RR}=0.79,95 \%$ CI $0.71-0.89$, respectively) (Figure 2A, 2B). However, there was some evidence of significant heterogeneity among the studies for specific $\left(P=0.003, I^{2}=67.6 \%\right)$ and overall mortality $(P=0.000$, $I^{2}=80.1 \%$ ). In order to test the robustness of our results, we also performed sensitivity analysis and the associations were not materially altered by an omission of one study at each time. Similar inverse associations were also observed for different levels of exercise. Six studies presented results on high vs low levels of pre-diagnosis physical activity and mortality. The pooled RR of 0.79 (95\% CI, 0.68-0.92) and 0.75 (95\% CI, 0.67-0.83) were found for cancer-specific and overall mortality, respectively (Figure 3A, 3B). There was no evidence of existing heterogeneity across studies. We found no obvious evidence of publication bias in any analyses by Begg's test.

In terms of physical activity after diagnosis, seven studies presented the relationship between prognosis of cancer survivors and physical activity levels after the diagnosis. Similar protective effects were also observed among analyses. Post-diagnosis physical activity was associated with more favorable CRC-specific survival $(\mathrm{RR}=0.77 ; 95 \% \mathrm{CI}, 0.63-0.94)$ (Figure 2C) and better overall survival $(\mathrm{RR}=0.71 ; 95 \% \mathrm{CI}, 0.63-0.81$ ) (Figure 2D) compared with non-exercisers. However, some evidence of heterogeneity among studies was observed. Therefore, we performed sensitivity analysis to test whether our results were robust. Removing anyone study at each time did not affect the overall outcomes substantially. When comparing high versus low levels physical activity after the diagnosis, we found the higher level of post-diagnosis physical activity was associated with lower CRC-specific mortality $(\mathrm{RR}=0.56 ; 95 \%$ CI, 0.38-0.83) (Figure 3C) and overall mortality (RR, 0.58; 95\% CI, 0.49-0.68) (Figure 3D). No evidence of heterogeneity was found among studies.

\section{DISCUSSION}

Based on 11 prospective cohort studies, our comprehensive meta-analysis indicated that both prediagnosis and post-diagnosis exercises were related to reduced risk of all-cause and cancer-specific death among cancer survivors. Furthermore, the higher levels of exercise also exerted survival benefits among CRC patients compared with low levels. Despite significant heterogeneity was existed among studies assessing patients between exercise and no-exercise, sensitivity analyses 
demonstrated the robustness of our overall outcomes. Our meta-analysis supported the hypothesis that exercise could reduce cancer mortality and improve prognosis, which was consistent with previous studies [18]. Given the paucity of data, whether changing in physical activity from before to after diagnosis was associated with favorable survival was still unclear, which might be more clinically relevant for patients and doctors. One study performed exploratory analysis, which consisted of 573 colorectal cancer women with stage I to III [10]. Compared to women with no change of their activity, those who increased their activity levels had better cancer-specific and overall prognosis, independent of the exercise level before diagnosis $(\mathrm{HR}=0.48,95 \% \mathrm{CI}, 0.24-0.97 ; \mathrm{HR}=0.51,95 \% \mathrm{CI}$, $0.30-0.85$, respectively) [10]. This indicated that patients could still benefit from exercise, even for those were in physical inactivity before diagnosis. Additional results from RCTs are needed to verify this association ultimately. In order to better characterize and support the biologic relationship between exercise and cancer survival, several observational studies recently focused on whether different molecular features of colorectal cancer could modify the associations between physical activity and survival [14, 19, 20]. Among 382 patients with PTGS2-positive colorectal cancer, the highest level of physical activity was associated with an $82 \%$ lower cancer-specific mortality compared with the least level. However, this protective association was disappeared among 223 patients with PTGS2-negative tumors [19]. Similarly, in another study, nuclear CTNNB1 negative colorectal cancer individuals who were active in exercises had a $67 \%$ lower risk of cancer-specific death compared with less active patients after the diagnosis, whereas post-diagnosis exercise was not related to lower mortality among patients who were nuclear CTNNB1-positive [20].

In spite of the protective link between physical activity and the incidence of colorectal cancer [18, 21], underlying biologic mechanisms among the inverse

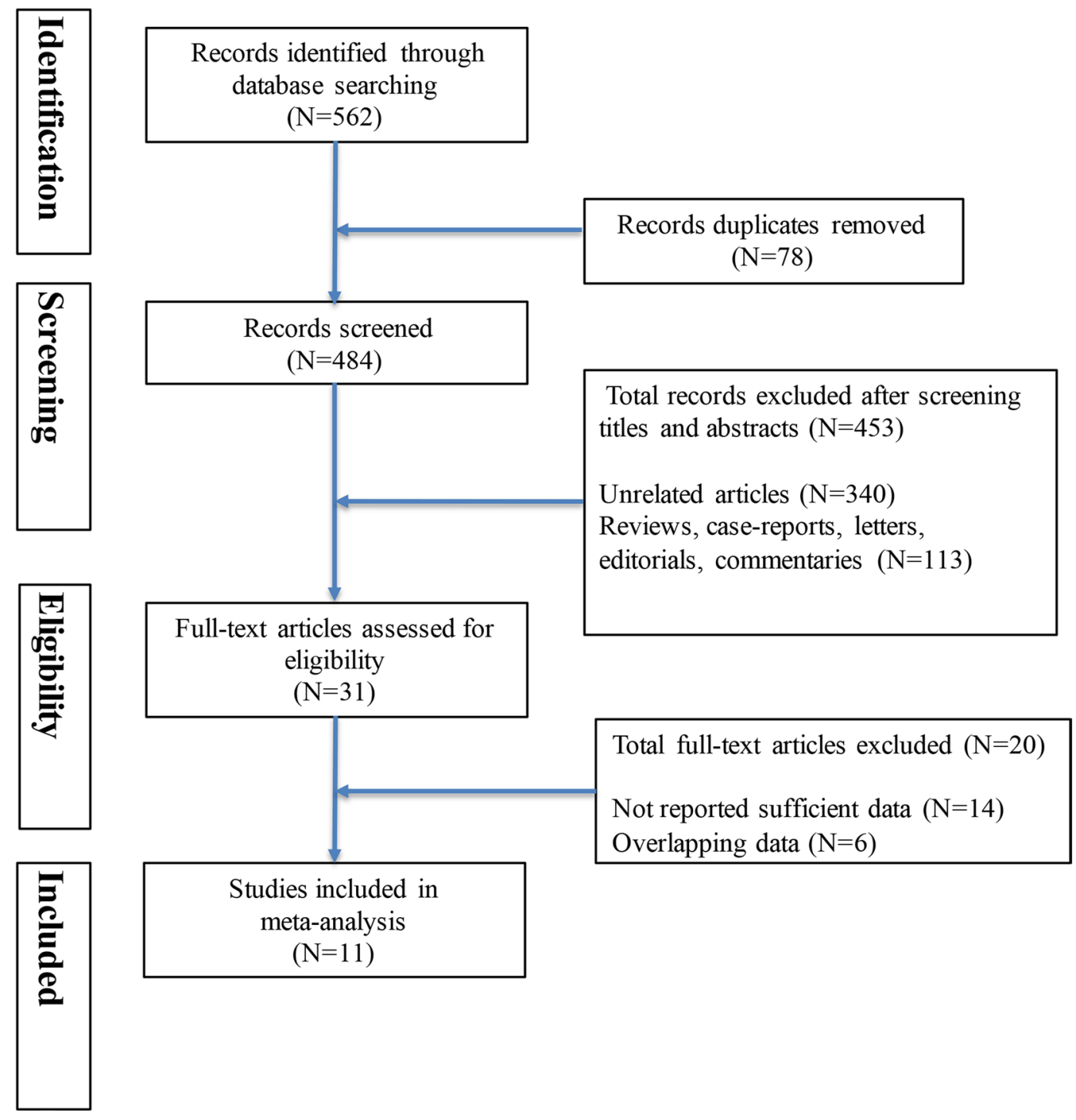

Figure 1: Flow diagram summarizing study identification and selection. 
Table 1: Characteristics of included studies assessing the relationship between physical activity and mortality of colorectal cancer patients

\begin{tabular}{|c|c|c|c|c|c|c|c|}
\hline Study & Design & Location & $\begin{array}{c}\text { Total } \\
\text { subjects }\end{array}$ & $\begin{array}{c}\text { Follow-up } \\
\text { period (years) }\end{array}$ & CRC Stage & $\begin{array}{l}\text { Timing assessment } \\
\text { of physical activity }\end{array}$ & $\begin{array}{c}\text { Confounding } \\
\text { variables adjusted }\end{array}$ \\
\hline Romaguera et al. 2015 & Cohort & Europe & 3292 & 4.2 & $\begin{array}{c}\text { I, II, } \\
\text { III, IV, unknown }\end{array}$ & Pre-diagnosis & $1,3,4,5,6,7,14$ \\
\hline Hardikar et al. 2015 & Cohort & USA & 1309 & 6.1 & $\begin{array}{c}\text { 0/I, II, } \\
\text { III }\end{array}$ & Pre-diagnosis & $1,2,3,6,8,7,14$ \\
\hline Arem et al. 2015 & Cohort & USA & 3,797 & 7.8 & $\begin{array}{l}\text { localize, regional } \\
\text { unknown }\end{array}$ & $\begin{array}{l}\text { Pre-diagnosis, } \\
\text { Post_diagnosis }\end{array}$ & $1,3,4,5,7,8,9,10,11,12,13$ \\
\hline Boyle et al. 2013 & Cohort & Australia & 879 & 5.6 & $\begin{array}{c}\text { I, II, } \\
\text { III, IV, unknown }\end{array}$ & Pre-diagnosis & $1,2,3,7,8,15,16$ \\
\hline Campbell et al. 2013 & Cohort & USA & 2,262 & 6.8 & $\begin{array}{l}\text { localized } \\
\text { regional }\end{array}$ & $\begin{array}{l}\text { Pre-diagnosis, } \\
\text { Post_diagnosis }\end{array}$ & $1,2,3,6,7,8,13,14,17$ \\
\hline Kuiper et al. 2012 & Cohort & USA & 1339 & 11.9 & $\begin{array}{c}\text { localized } \\
\text { regional }\end{array}$ & $\begin{array}{l}\text { Pre-diagnosis, } \\
\text { Post—diagnosis }\end{array}$ & $2,3,6,7,8,19,20,21,22$ \\
\hline Baade et al. 2011 & Cohort & Australia & 1825 & 4.9 & $\begin{array}{c}\text { I, II, } \\
\text { III, unknown }\end{array}$ & Post—diagnosis & $1,2,3,5,6,7,8,9,10,11$ \\
\hline Meyerhardt et al. 2009 & Cohort & USA & 661 & 8.6 & $\begin{array}{c}\text { I, II, } \\
\text { III, Missing (not } \\
\text { metastatic) }\end{array}$ & Post—diagnosis & $2,3,4,5,7,8,14,18,24$ \\
\hline $\begin{array}{l}\text { Meyerhardt et al. } \\
\text { 2006(NHS) }\end{array}$ & Cohort & USA & 573 & 9.6 & $\begin{array}{l}\text { I, II, } \\
\text { III }\end{array}$ & $\begin{array}{l}\text { Pre-diagnosis, } \\
\text { Post—diagnosis }\end{array}$ & $2,3,4,5,7,8,11,14,18,24$ \\
\hline Haydon et al. 2006 & Cohort & Australia & 526 & 5.5 & $\begin{array}{c}\text { I, II, } \\
\text { III, IV, unknown }\end{array}$ & Pre-diagnosis & $1,2,3$ \\
\hline $\begin{array}{l}\text { Meyerhardt et al. } \\
\text { 2006(CALGB) }\end{array}$ & Cohort & USA & 832 & 3.8 & III & Post—diagnosis & $1,2,3,4,8,23,24,25,26$ \\
\hline
\end{tabular}

Abbreviations: 1. sex, 2. age, 3. tumor stage, 4. tumor grade, 5. tumor site, 6. educational, 7. smoking, 8. BMI, 9. surgery, 10. radiation, 11. chemotherapy, 12. self-reported health, 13. time of watching TV/sitting, 14. year of diagnosis, 15. socioeconomic status, 16. diabetes, 17.red meat intake, 18. change in body mass index before and after diagnosis, 19. study arm, 20. alcohol, 21. hormone therapy use, 22. ethnicity, 23. presence of clinical perforation or obstruction at time of surgery, 24. time from diagnosis to physical activity measurement, 25. baseline performance status, 26. baseline CEA.

relationship are less apparent. Several potential plausible mechanisms are posited to explain this protective influence of physical activity on prognosis of cancer survivors. For example, Some intervention studies reported exercise may reduce plasma insulin levels and increase insulin sensitivity $[22,23]$, thus attenuating hyperinsulinemia [24]. It was well documented that the high levels of insulin and insulinlike growth factors (IGF) were associated with malignancy growth, angiogenesis, and metastasis in vitro and animal studies [25-27]. Reduction of insulin and IGF levels could reduce the risk of CRC and improve survival outcomes $[28,29]$. In addition, physical activity may reduce systemic levels of inflammation and improve immune function, which was supported by recent studies [29-31]. It was reported that regular exercise reduces the volumes and recurrence of five different tumors in mice through nature killer cell activation [30]. Furthermore, physical activity also improved tolerance of surgery or adjuvant treatment and reduced risks of comorbid conditions [8].

The strength of our systematic analysis was included comprehensive prospective studies and large numbers of patients, together with the assessment of the difference among survival benefits between pre- and post-diagnosis. However, our meta-analysis had several limitations that merit further consideration. First, our meta-analysis pooled data from observational studies, which had some methodical shortcomings and were prone to cause reverse causality. CRC patients who had less physical activity may be due to the severity of the disease at the time of physical activity assessment. In order to minimize this possibility of reverse causation, we adopted adjusted RRs and excluded patients at CRC IV stage. Second, exposure assessment of physical activity was self-reported or interview-based, which inevitably introduced some measurement errors into studies. Accurate measurement of physical activity is needed in further epidemiologic studies. Third, there was a significant heterogeneity in our analysis. Although we performed sensitivity analyses and overall outcomes did not materially alter, results of our analyses need to be interpreted with caution.

This meta-analysis strengthens the protective role of physical activity as a promising candidate for CRC therapeutics among cancer survivors. However, it remains unknown that how effects of physical activity, including 
Table 2: Newcastle-Ottawa scale for assessment of quality of in included Cohort studies

\begin{tabular}{|c|c|c|c|c|c|c|c|c|c|}
\hline \multirow[b]{3}{*}{ Author } & \multicolumn{8}{|c|}{ Quality assessment criteria } & \multirow[b]{3}{*}{$\begin{array}{c}\text { Overall } \\
\text { Quality } \\
\text { Score } \\
(\max =9)\end{array}$} \\
\hline & \multicolumn{4}{|c|}{ selection } & \multirow{2}{*}{$\begin{array}{l}\text { Comparability } \\
\text { Study control } \\
\text { for age/gender } \\
\text { and additional } \\
\text { factor? }\end{array}$} & \multicolumn{3}{|c|}{ Outcome } & \\
\hline & $\begin{array}{l}\text { Representativeness } \\
\text { of exposed cohort? }\end{array}$ & $\begin{array}{l}\text { Selection } \\
\text { of the } \\
\text { non- } \\
\text { exposed } \\
\text { cohort? }\end{array}$ & $\begin{array}{l}\text { Ascertainment } \\
\text { of exposure? }\end{array}$ & $\begin{array}{c}\text { outcome } \\
\text { of interest } \\
\text { was not } \\
\text { present } \\
\text { at start of } \\
\text { study? }\end{array}$ & & $\begin{array}{c}\text { Assessment } \\
\text { of } \\
\text { outcome? }\end{array}$ & $\begin{array}{l}\text { Was } \\
\text { follow- } \\
\text { up long } \\
\text { enough for } \\
\text { outcome } \\
\text { to occur? }\end{array}$ & $\begin{array}{c}\text { Adequacy } \\
\text { of follow- } \\
\text { up of } \\
\text { cohorts? }\end{array}$ & \\
\hline $\begin{array}{l}\text { Romaguera } \\
\text { et al. } 2015\end{array}$ & $*$ & $*$ & * & $*$ & $* *$ & $*$ & $*$ & * & 9 \\
\hline $\begin{array}{l}\text { Hardikar } \\
\text { et al. } 2015\end{array}$ & $*$ & $*$ & $*$ & $*$ & $* *$ & $*$ & * & - & 8 \\
\hline $\begin{array}{l}\text { Arem } \\
\text { et al. } 2014\end{array}$ & * & $*$ & * & $*$ & $* *$ & $*$ & $*$ & - & 8 \\
\hline $\begin{array}{l}\text { Boyle } \\
\text { et al. } 2013\end{array}$ & $*$ & $*$ & * & $*$ & $* *$ & $*$ & $*$ & $*$ & 9 \\
\hline $\begin{array}{l}\text { Campbell } \\
\text { et al. } 2013\end{array}$ & $*$ & $*$ & * & $*$ & $* *$ & * & $*$ & - & 8 \\
\hline $\begin{array}{l}\text { Kuiper } \\
\text { et al. } 2012\end{array}$ & - & $*$ & * & $*$ & $* *$ & $*$ & $*$ & - & 7 \\
\hline $\begin{array}{l}\text { Baade } \\
\text { et al. } 2011\end{array}$ & $*$ & $*$ & * & $*$ & $* *$ & $*$ & - & - & 7 \\
\hline $\begin{array}{l}\text { Meyerhardt } \\
\text { et al. } 2009\end{array}$ & - & $*$ & $*$ & * & $* *$ & $*$ & $*$ & $*$ & 8 \\
\hline $\begin{array}{l}\text { Meyerhardt } \\
\text { et al. } 2006 \\
\text { (NHS) }\end{array}$ & - & $*$ & $*$ & $*$ & $* *$ & $*$ & $*$ & - & 7 \\
\hline $\begin{array}{l}\text { Meyerhardt } \\
\text { et al. } 2006 \\
\text { (CALGB) }\end{array}$ & - & $*$ & $*$ & $*$ & $* *$ & $*$ & $*$ & $*$ & 8 \\
\hline $\begin{array}{l}\text { Haydon } \\
\text { et al. } 2006\end{array}$ & $*$ & $*$ & $*$ & $*$ & $* *$ & $*$ & $*$ & $*$ & 9 \\
\hline
\end{tabular}

Each asterisk represents if individual criterion within the subsection were fulfilled.

duration, intensity and types of activity, will vary on survival outcomes and which type of CRC among patients is most likely to benefit from exercises. In addition, it is largely unclear whether the effect of post-diagnostic physical activity on CRC survival is influenced by patients' pre-diagnostic levels. In future, large prospective observational studies and RCTs with accurate assessment of physical activity and sufficiently long follow-up durations are needed to elucidate those questions.

In conclusion, the current systematic analysis showed that physical activity, both before and after colorectal cancer diagnosis, was associated with a lower risk of mortality and improved survival of CRC survivors. This finding extended our current evidence and supported the promising role of physical activity on better prognosis of cancer survivors. In the meantime, it may be rational to recommend cancer survivors to adopt moderate levels of physical activity in their lifestyle. Further researches, however, are warranted to examine this beneficial effect before a definite conclusion can be reached.

\section{MATERIALS AND METHODS}

This meta-analysis was reported according to the Preferred Reporting Items for Systematic Reviews and Meta-Analysis (PRISMA) guidelines [32].

\section{Search strategy}

We (WWR and GFF.) independently performed a literature search in PubMed, Cochrane Library databases and Web of Science for all relevant studies before Jan 2016. The following keywords were adopted in this search procedure: 'colorectal cancer', 'colon cancer', 'rectal cancer', 'colorectal adenocarcinoma', 'exercise', 'physical activity', 'motor activity', 'survival', 'prognosis', 

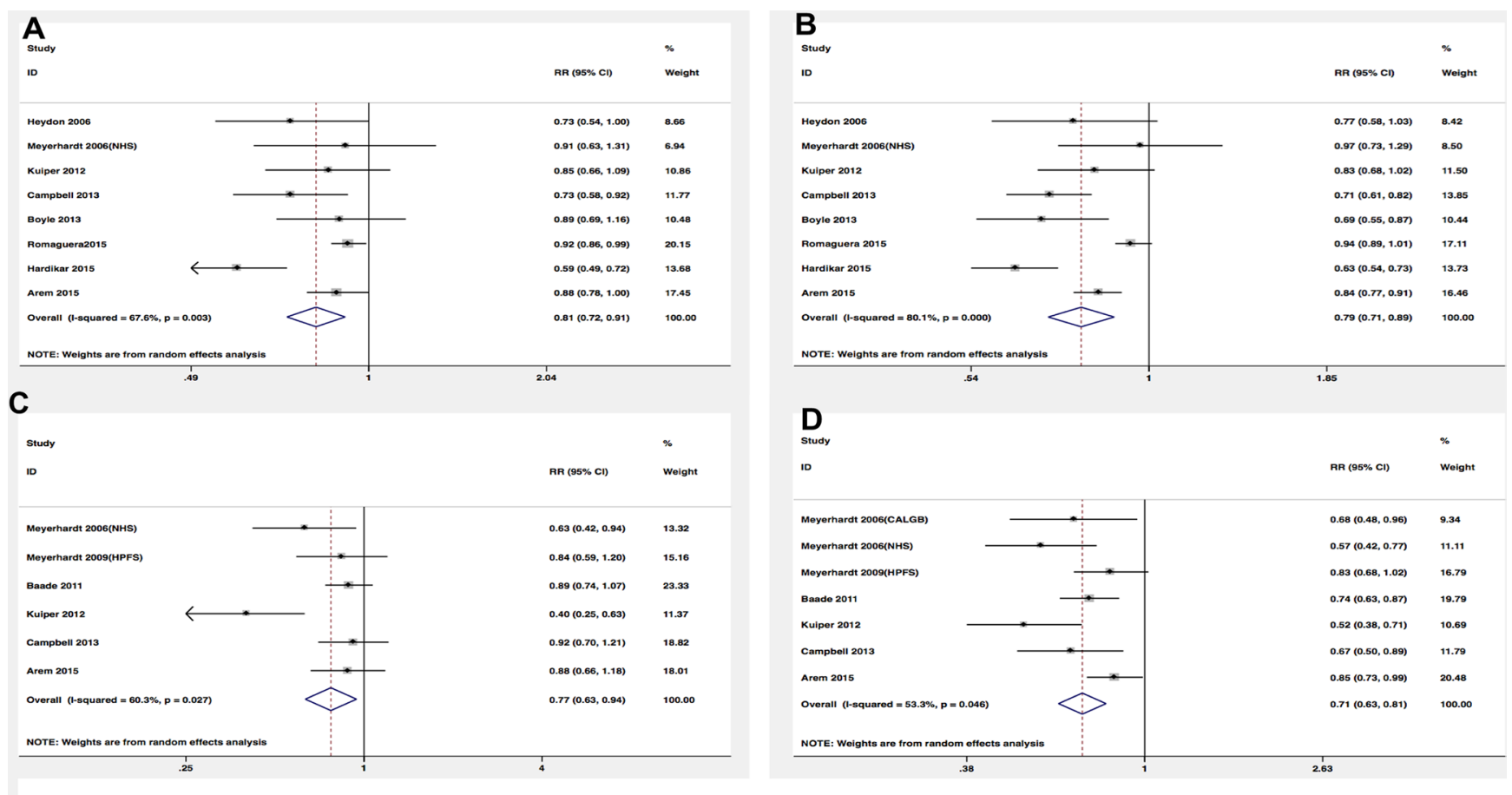

Figure 2: Relative risks for the association between physical activity and survival among exercise patients VS non-exercise patients. (A) Pre-diagnosis and CRC-specific mortality; (B) Pre-diagnosis and overall mortality; (C) Post-diagnosis and CRC-specific mortality; (D) Post-diagnosis and overall mortality.
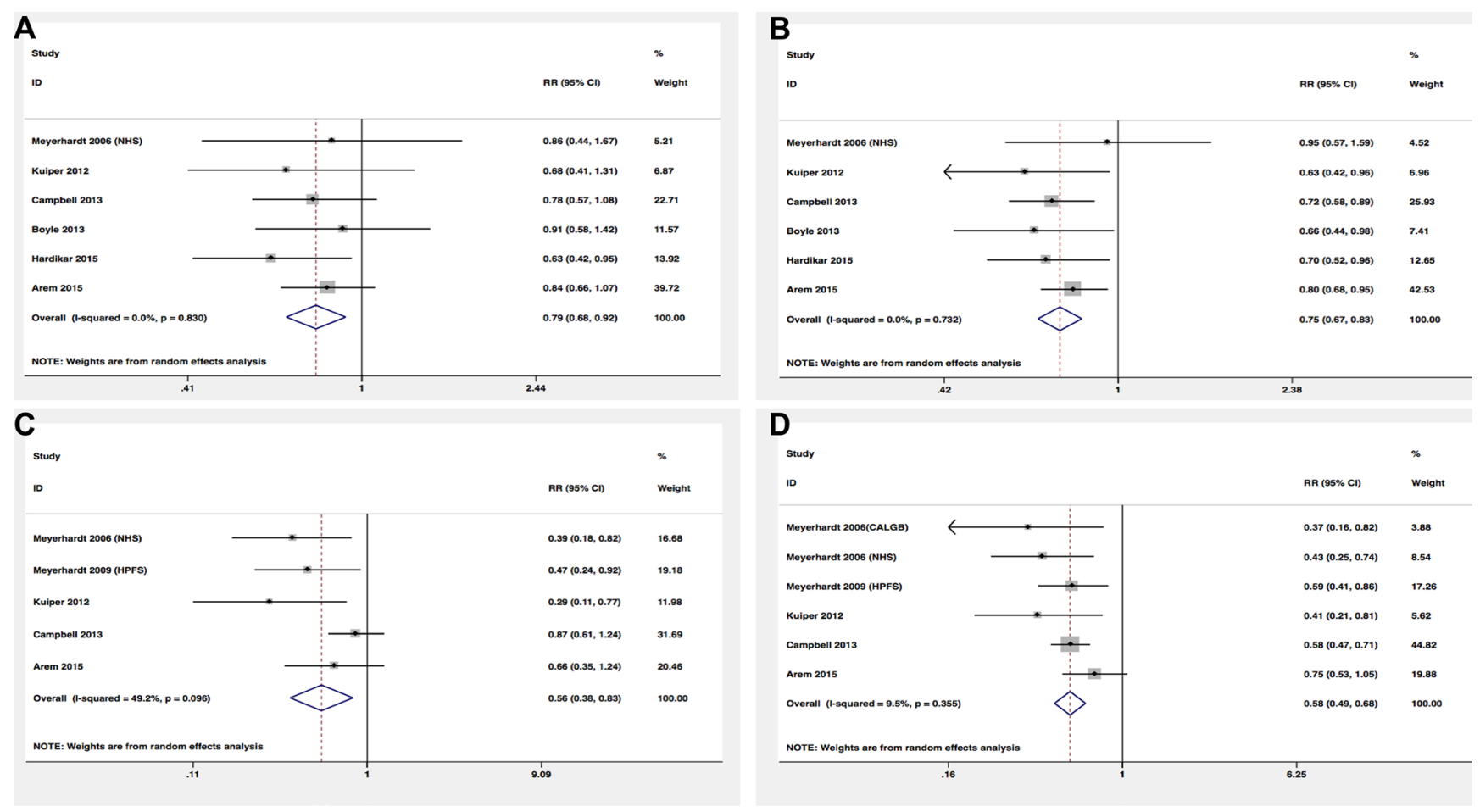

Figure 3: Relative risks for the association between physical activity and survival among high-level VS low-level. (A) Pre-diagnosis and CRC-specific mortality; (B) Pre-diagnosis and overall mortality; (C) Post-diagnosis and CRC-specific mortality; (D) Post-diagnosis and overall mortality. 
'recurrence', and 'mortality'. Two authors screened the titles and abstracts of articles identified in the search and excluded unrelated articles independently. We further scrutinized the remaining full articles and lists of references in lest we ignored some additional relevant studies.

\section{Eligibility criteria}

Two authors performed eligibility assessment in a standardized manner independently. The inclusion criteria were set in advance. The article was included in this metaanalysis if they met the following criteria:(1) original article that evaluated association between physical activity and CRC; (2) study that reported relative risk (RR) with $95 \% \mathrm{CI}$; (3) the exposure of physical activity was assessed before or after diagnosis of CRC; (4) the interesting outcomes were overall mortality or colorectal cancerspecific mortality. If there were multiple publications which were overlapped or duplicated, we extracted the information from the most comprehensive study. Any discrepancies in the study selection were resolved by discussions or reviewing of the original article.

\section{Data extraction and quality assessment}

Two authors (WWR and GFF.) extracted data from included articles independently and the results were crosschecked. Following information was extracted in each individual article: authors, years, design, location, the number of total subjects, follow-up period, colorectal cancer stage, timing assessment of physical activity, and confounding variables adjusted. We contacted authors for important information by email if the required data were unavailable.

The Newcastle-Ottawa Scale was applied for quality assessment in order to understand the risk of bias among articles. Two authors independently performed all methodological quality of eligible studies. Any disagreements were resolved by discussions or with a third author.

\section{Statistical analysis}

We calculated pooled RRs for physical activity before and after diagnosis in relation to overall or CRCspecific mortality using the DerSimonian and Laird random-effects models [33], since the heterogeneity across studies was considerable. We adopted adjusted RRs reported in studies for meta-analysis in order to reduce the bias. Two methods were applied to calculated heterogeneity among each study [34]. Cochran's Q statistic and $I^{2}$. If $P$ value $<0.1$ or $I^{2}$ values $>50 \%$, statistically significance for heterogeneity was considered [34, 35]. The sensitivity analysis was performed through eliminating each study every time and calculated the pooled RRs for remaining studies in order to evaluate whether the results were affected by a single study. Potential publication bias was assessed by Begg's test. In addition, we investigated whether the degree of physical activity would influence survival outcomes of CRC patients. A $P$ level $<0.05$ (except for Cochran's $Q$ test) was considered statistically significant and all $P$ values were two tailed. All statistical analyses were conducted using Stata software version 13.0 (Stata Corporation, College Station, Tex).

\section{CONFLICTS OF INTEREST}

No potential competing interest.

\section{Authors' contributions}

LLJ and WWR contributed to conception and design of the study. WWR, GFF, YJZ and LYT contributed to the data acquisition, analysis and interpretation of the data. WWR, FDQ, GJ and SD contributed to writing and editing the manuscript. All authors commented on drafts of the paper and have approved the final draft of the manuscript.

\section{REFERENCES}

1. Siegel R, DeSantis C, Virgo K, Stein K, Mariotto A, Smith T, Cooper D, Gansler T, Lerro C, Fedewa S, Lin C, Leach C, Cannady RS, et al. Cancer treatment and survivorship statistics, 2012. CA Cancer J Clin. 2012; 62:220-241.

2. Siegel R, Desantis C, Jemal A. Colorectal cancer statistics, 2014. CA Cancer J Clin. 2014; 64:104-117.

3. DeSantis CE, Lin CC, Mariotto AB, Siegel RL, Stein KD, Kramer JL, Alteri R, Robbins AS, Jemal A. Cancer treatment and survivorship statistics, 2014. CA Cancer J Clin. 2014; 64:252-271.

4. Boyle T, Keegel T, Bull F, Heyworth J, Fritschi L. Physical activity and risks of proximal and distal colon cancers: a systematic review and meta-analysis. J Natl Cancer Inst. 2012; 104:1548-1561.

5. Wolin KY, Yan Y, Colditz GA, Lee IM. Physical activity and colon cancer prevention: a meta-analysis. Br J Cancer. 2009; 100:611-616.

6. Fong DY, Ho JW, Hui BP, Lee AM, Macfarlane DJ, Leung SS, Cerin E, Chan WY, Leung IP, Lam SH, Taylor AJ, Cheng KK. Physical activity for cancer survivors: meta-analysis of randomised controlled trials. BMJ. 2012; 344:e70.

7. Romaguera D, Ward H, Wark PA, Vergnaud AC, Peeters PH, van Gils CH, Ferrari P, Fedirko V, Jenab M, BoutronRuault MC, Dossus L, Dartois L, Hansen CP, et al. Prediagnostic concordance with the WCRF/AICR guidelines and survival in European colorectal cancer patients: a cohort study. BMC Med. 2015; 13:107.

8. Campbell PT, Patel AV, Newton CC, Jacobs EJ, Gapstur SM. Associations of recreational physical activity and leisure time spent sitting with colorectal cancer survival. J Clin Oncol. 2013; 31:876-885. 
9. Boyle T, Fritschi L, Platell C, Heyworth J. Lifestyle factors associated with survival after colorectal cancer diagnosis. Br J Cancer. 2013; 109:814-822.

10. Meyerhardt JA, Giovannucci EL, Holmes MD, Chan AT, Chan JA, Colditz GA, Fuchs CS. Physical activity and survival after colorectal cancer diagnosis. J Clin Oncol. 2006; 24:3527-3534.

11. Haydon AM, Macinnis RJ, English DR, Giles GG. Effect of physical activity and body size on survival after diagnosis with colorectal cancer. Gut. 2006; 55:62-67.

12. Arem H, Pfeiffer RM, Engels EA, Alfano CM, Hollenbeck A, Park Y, Matthews CE. Pre- and postdiagnosis physical activity, television viewing, and mortality among patients with colorectal cancer in the National Institutes of Health-AARP Diet and Health Study. J Clin Oncol. 2015; 33:180-188.

13. Kuiper JG, Phipps AI, Neuhouser ML, Chlebowski RT, Thomson CA, Irwin ML, Lane DS, Wactawski-Wende J, Hou L, Jackson RD, Kampman E, Newcomb PA. Recreational physical activity, body mass index, and survival in women with colorectal cancer. Cancer Causes Control. 2012; 23:1939-1948.

14. Hardikar S, Newcomb PA, Campbell PT, Win AK, Lindor NM, Buchanan DD, Makar KW, Jenkins MA, Potter JD, Phipps AI. Prediagnostic Physical Activity and Colorectal Cancer Survival: Overall and Stratified by Tumor Characteristics. Cancer Epidemiol Biomarkers Prev. 2015; 24:1130-1137.

15. Baade PD, Meng X, Youl PH, Aitken JF, Dunn J, Chambers SK. The impact of body mass index and physical activity on mortality among patients with colorectal cancer in Queensland, Australia. Cancer Epidemiol Biomarkers Prev. 2011; 20:1410-1420.

16. Meyerhardt JA, Giovannucci EL, Ogino S, Kirkner GJ, Chan AT, Willett W, Fuchs CS. Physical activity and male colorectal cancer survival. Arch Intern Med. 2009; 169:2102-2108.

17. Meyerhardt JA, Heseltine D, Niedzwiecki D, Hollis D, Saltz LB, Mayer RJ, Thomas J, Nelson H, Whittom R, Hantel A, Schilsky RL, Fuchs CS. Impact of physical activity on cancer recurrence and survival in patients with stage III colon cancer: findings from CALGB 89803. J Clin Oncol. 2006; 24:3535-3541.

18. Je Y, Jeon JY, Giovannucci EL, Meyerhardt JA. Association between physical activity and mortality in colorectal cancer: a meta-analysis of prospective cohort studies. Int J Cancer. 2013; 133:1905-1913.

19. Yamauchi M, Lochhead P, Imamura Y, Kuchiba A, Liao X, Qian ZR, Nishihara R, Morikawa T, Shima K, Wu K, Giovannucci E, Meyerhardt JA, Fuchs CS, et al. Physical activity, tumor PTGS2 expression, and survival in patients with colorectal cancer. Cancer Epidemiol Biomarkers Prev. $2013 ; 22: 1142-1152$.
20. Morikawa T, Kuchiba A, Yamauchi M, Meyerhardt JA, Shima K, Nosho K, Chan AT, Giovannucci E, Fuchs CS, Ogino S. Association of CTNNB1 (beta-catenin) alterations, body mass index, and physical activity with survival in patients with colorectal cancer. Jama. 2011; 305:1685-1694.

21. Samad AK, Taylor RS, Marshall T, Chapman MA. A metaanalysis of the association of physical activity with reduced risk of colorectal cancer. Colorectal Dis. 2005; 7:204-213.

22. Kim ES, Im JA, Kim KC, Park JH, Suh SH, Kang ES, Kim SH, Jekal Y, Lee CW, Yoon YJ, Lee HC, Jeon JY. Improved insulin sensitivity and adiponectin level after exercise training in obese Korean youth. Obesity (Silver Spring). 2007; 15:3023-3030.

23. Helmrich SP, Ragland DR, Leung RW, Paffenbarger RS Jr. Physical activity and reduced occurrence of noninsulin-dependent diabetes mellitus. N Engl J Med. 1991; 325:147-152.

24. Giovannucci E. Insulin, insulin-like growth factors and colon cancer: a review of the evidence. J Nutr. 2001; 131:3109S-3120S.

25. Sandhu MS, Dunger DB, Giovannucci EL. Insulin, insulinlike growth factor-I (IGF-I), IGF binding proteins, their biologic interactions, and colorectal cancer. J Natl Cancer Inst. 2002; 94:972-980.

26. Warren RS, Yuan H, Matli MR, Ferrara N, Donner DB. Induction of vascular endothelial growth factor by insulinlike growth factor 1 in colorectal carcinoma. J Biol Chem. 1996; 271:29483-29488.

27. Wu Y, Yakar S, Zhao L, Hennighausen L, LeRoith D. Circulating insulin-like growth factor-I levels regulate colon cancer growth and metastasis. Cancer Res. 2002; 62:1030-1035.

28. Sax AT, Jenkins DG, Devin JL, Hughes GI, Bolam KA, Skinner TL. The insulin-like growth factor axis: A biological mechanism linking physical activity to colorectal cancer survival. Cancer Epidemiol. 2014; 38:455-459.

29. Bradley RL, Jeon JY, Liu FF, Maratos-Flier E. Voluntary exercise improves insulin sensitivity and adipose tissue inflammation in diet-induced obese mice. Am J Physiol Endocrinol Metab. 2008; 295:E586-594.

30. Pedersen L, Idorn $\mathrm{M}$, Olofsson $\mathrm{GH}$, Lauenborg B, Nookaew I, Hansen RH, Johannesen HH, Becker JC, Pedersen KS, Dethlefsen C, Nielsen J, Gehl J, Pedersen BK, et al. Voluntary Running Suppresses Tumor Growth through Epinephrine- and IL-6-Dependent NK Cell Mobilization and Redistribution. Cell Metab. 2016.

31. Fairey AS, Courneya KS, Field CJ, Bell GJ, Jones LW, Mackey JR. Randomized controlled trial of exercise and blood immune function in postmenopausal breast cancer survivors. J Appl Physiol (1985). 2005; 98:1534-1540.

32. Liberati A, Altman DG, Tetzlaff J, Mulrow C, Gotzsche PC, Ioannidis JP, Clarke M, Devereaux PJ, Kleijnen J, Moher D. The PRISMA statement for reporting systematic 
reviews and meta-analyses of studies that evaluate health care interventions: explanation and elaboration. J Clin Epidemiol. 2009; 62:e1-34.

33. DerSimonian R, Kacker R. Random-effects model for metaanalysis of clinical trials: an update. Contemp Clin Trials. 2007; 28:105-114.
34. Higgins JP, Thompson SG. Quantifying heterogeneity in a meta-analysis. Stat Med. 2002; 21:1539-1558.

35. Higgins JP, Thompson SG, Deeks JJ, Altman DG. Measuring inconsistency in meta-analyses. BMJ. 2003; 327:557-560. 